though not necessarily of intention, by the hotel and catering courses developed largely through the work of the Institute and its predecessors.

It is perhaps legitimate to touch upon the aspirations stimulated by these courses, because the teaching of subjects such as nutrition to students and teachers is undoubtedly creating a new climate of opinion in the industry itself. The industry, through its students and teachers, has been brought in touch with many of the principles underlying their work, which had previously received but cursory attention. Hygiene, nutrition, and science are today subjects of significance, not only in the curricula of technical colleges, but in the programmes of practical hotel keepers and caterers themselves. The industry has rubbed shoulders with teachers of domestic science, teachers of nutrition and teachers of accounts and other subjects, and there has been give and take on both sides. The Institute, representing the industry, foresees and hopes for the day when the teaching of hotel and catering subjects will be entirely in the hands of those properly trained in the industry and as teachers, but meanwhile it recognizes the vast debt it owes for help from teachers in other fields, particularly domestic science. It has profited from this give and take, and it is certain that, among the many subjects given heightened significance by these contacts, nutrition is prominent.

\title{
REFERENCE
}

Lumby, A. (1953). Proc. Nutr. Soc., 12, 186.

\section{The Royal Sanitary Institute Certificate in Nutrition}

\author{
By H. E. Magee, Ministry of Health, 23 Savile Row, London, W.I
}

\begin{abstract}
Postwar need
Towards the end of World War II it became increasingly evident that courses in elementary nutrition and dietetics were needed for people who had been concerned in one way or another with community feeding, as in industrial and other canteens, in hospitals and schools and residential institutions. It soon became clear that the demand for such courses would increase with the end of the war. The anticipation proved to be true and large numbers of demobilized men and women, who had been working at catering, cooking or serving food in messes, hospitals and canteens, made it known that they would welcome instruction of a practical nature in nutrition and dietetics. Technical schools and institutes were obviously the most suitable places for their purpose, and inquiries made in some of them showed that they would welcome the chance to give such courses provided it would lead, after a suitable examination, to a certificate or diploma conferred by a responsible and authoritative organization. The Royal Sanitary Institute on being approached by The Nutrition Society in January 1945 expressed its willingness to conduct examinations in several centres throughout the country and to award an official certificate of the
\end{abstract}


Institute to successful candidates. A joint committee of the Society and of the R.S.I. was appointed to draw up a syllabus of instruction, to prepare conditions for the recognition of courses, to prepare a syllabus of examination and to approve examiners. An examination subcommittee has been formed also to scrutinize questions and draw up examination papers.

\section{The training course}

The course of training approved by the Committee requires not less than $\mathrm{I} 20 \mathrm{~h}$ of theoretical and practical instruction, either whole or part-time, to be completed in not more than I year. The instruction is to be given in the form of lectures, demonstrations, discussions, and practical work in the laboratory and kitchen, and visits to selected institutions, such as hotels and hospitals, are recommended. The curriculum covers the basic principles of nutrition and their application, the composition of food, its digestion, absorption and metabolism, nutritional requirements and food in relation to physique and health, the effects of cooking on food, principles of catering, construction of menus, the use of food tables and the planning of balanced meals for various types of person. Instruction is given also in the modifications of diet required for persons suffering from chronic gastric disease, the effects of preservation and storage on the nutritive value of foods and the cost of essential nutrients and its effect on the composition of family diets.

The course is intended to set out in an elementary way the fundamentals of the subject and to impart to students an awareness of the importance of nutrition in cooking and catering, so that they will view their work from a nutritional rather than from a purely technical angle. This is perhaps the most significant objective of the certificate because, if it succeeds in enabling those charged with the feeding of groups of people to think, plan and execute in accordance with physiological principles, those who are fed will benefit.

At present, courses of instruction are proceeding in fifteen towns in England and Wales and one in Scotland. In London, five technical schools are participating. In 1946 , the ist year of the course, thirty certificates were granted, in $195^{\circ}$ the number had risen to IOI; there has since been a slight falling off and last year sixty-six passed. Formerly examinations were held annually in two centres, but during the present year they will be in four.

The Committee will not approve any curriculum unless the staff of the institute includes one teacher competent to deal with the physiology of nutrition and one with practical dietetics, including cooking. 'The corps of examiners is paired in the same way, and each candidate is given an oral examination by one representing physiology and one practical dietetics.

The standard of knowledge of candidates at examination has been found to be surprisingly high, the proportion of failures being rarely above about $10 \%$ The certificate has been found helpful to applicants for posts in catering, cooking and advisory work. All the indications are that the course of instruction and the certificate are much appreciated and are serving a useful purpose.

The advantages of ensuring as far as possible that persons concerned with feeding 
groups of people possess some knowledge of nutrition and dietetics are self-evident and require no argument. The Society was convinced at the time that the establishment of courses and an authoritative certificate in nutrition and dietetics would be of benefit to substantial numbers of people. The success of this venture of the Society into the educational field has vindicated that belief, but the Society as such no longer has any responsibility for the teaching or the examinations, which now belongs to the Royal Sanitary Institute, where the work is carried out efficiently and well.

\section{Nutrition in Hospital Catering}

\section{By C. C. A. Gibbs, King Edward's Hospital Fund for London School of Hospital} Catering, St. Pancras Hospital, London, N.W.I

\section{Diet and the sick}

It is estimated that in the hospitals of Great Britain there are about half a million patients, and that the staff that looks after them, directly or indirectly, numbers also about half a million. This important section of the public consumes, therefore, about three million meals a day, and in no sphere of catering could it be said that the application of sound nutritional principles was more essential. A proportion of the meals comes within the category of special diets, and as such is the responsibility of the therapeutic dietitian.

It may be asked why hospitals have not led the way in food education, for surely in no more suitable place could people be taught the elementary principles of good feeding. Unfortunately hospitals, far from leading, have until comparatively recently shown little desire to seize the opportunity to advance the knowledge of nutrition. Fortunately, however, nutritionists have taken the initiative and, as a result of their unceasing efforts, hospital authorities have become increasingly conscious of the remedial value of good feeding.

\section{Investigations and reports}

In the campaign for raising the standard of hospital feeding, the King Edward's Hospital Fund for London have taken an active part. In I 943 they undertook, in collaboration with several London hospitals, a survey of the diet provided for patients and staff; details of the survey were given in their first memorandum on hospital diet published that year, the main purpose of which was to draw the attention of the authorities to the need for reviewing the diet provided in hospitals, in the light of recent advances in the science of nutrition.

Encouraged by the interest taken by the hospitals, and in the light of further study of the many problems presented, the Fund published, in 1945, a second memorandum, which dealt in greater detail with the whole organization of the catering department, one of its main recommendations being that catering in all its processes should be regarded as a separate department of the hospital, in the 